\title{
El conocimiento lógico matemático
}

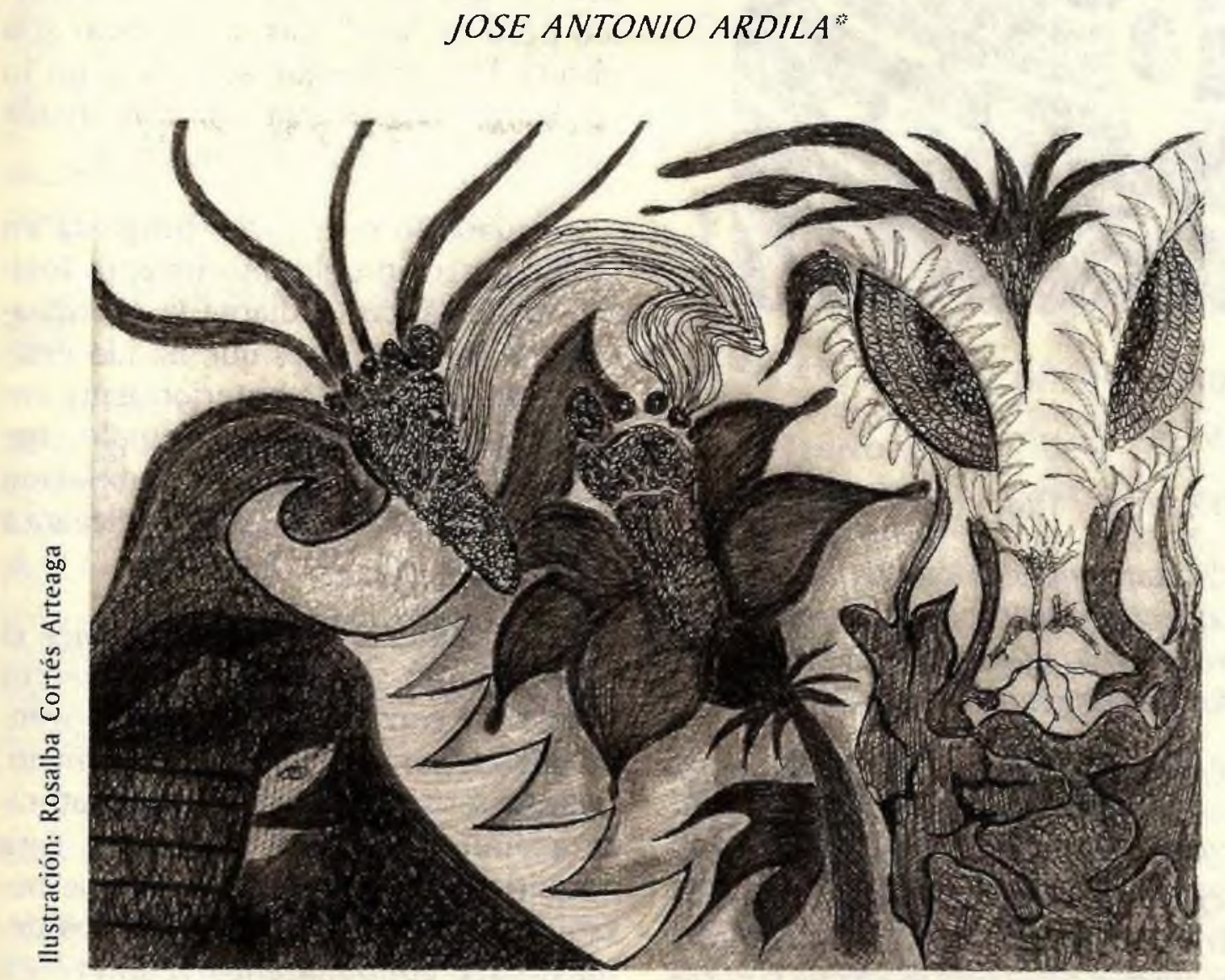

Resumen

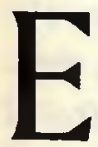

propósito de este artículo se centra en mostrar la diferencia que existe entre, el conocimiento lógico - matemático y el social, por cuanto ésta, es fundamental para poder

Profesor de Matemáticas. Universidad Surcolombiana. orientar de una manera significativa la enseñanza de la matemática.

Además, relato algunas experiencias que he tenido con niños en las que, se refuerzan los temas anteriormente mencionados y enfatizo sobre la importancia de respetar la actuación y el razonamiento de nuestros alumnos para efectos del aprendizaje. 


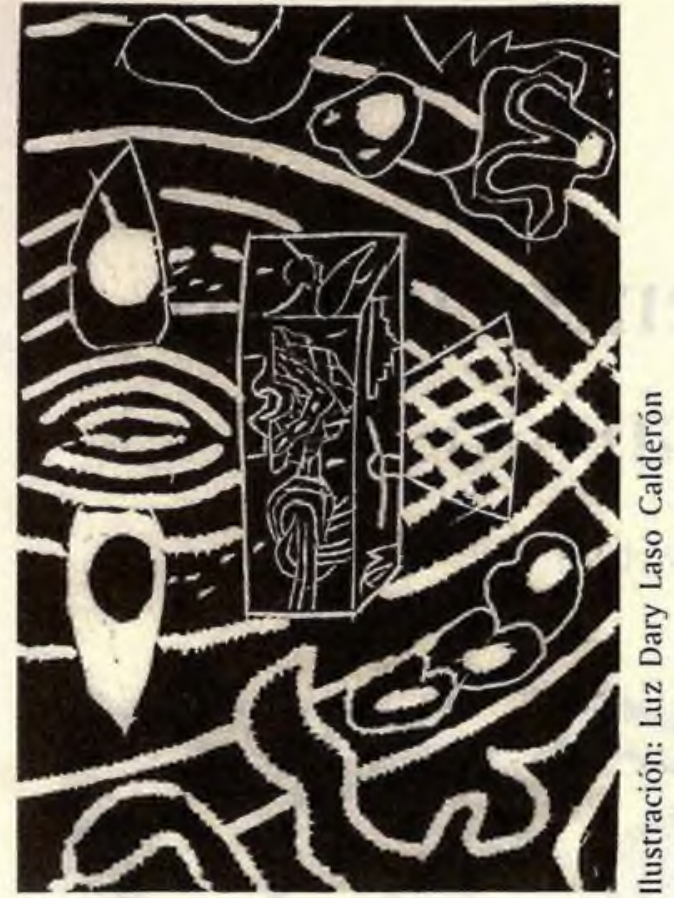

El conocimiento lógico matemático

(Kamii, C, 1985), dice así:

"El conocimiento lógico - matemático y el conocimiento fisico son dos tipos principales o polos, del conocimiento distinguidos por Piaget.

El conocimiento fisico es el conocimiento de los objetos de la realidad exterior (P 21). El calor y el peso de una ficha son ejemplos de propiedades fisicas que están en los objetos de la realidad exterior y que pueden conocerse mediante la observación. El conocimiento de que una ficha caerá cuando la soltemos en el aire es un ejemplo de conocimiento físico".

En la misma página, agrega: "el conocimiento lógico - matemático se compone de relaciones construidas por cada individuo". Por ejemplo, cuando se nos muestran dos canicas, una roja y otra azul y creemos que son diferentes, esta diferencia es un ejemplo de los fundamentos del conocimiento lógico - ma- temático. Las canicas son realmente observables pero la diferencia entre ellas no lo es. La diferencia es una relación creada mentalmente, por el individuo que establece esta relación entre los dos objetos. La diferencia no esta ni en la canica roja ni en la azul y si una persona no estableciera esta relación entre los objetos, no habría para ella ninguna relación. También puede decirse que son "similares", "del mismo peso" y "dos". Las dos canicas son observables, pero que son "dos" no lo es. El número es una relación creada mentalmente para cada individuo.

El párvulo o el joven progresa en la construcción del conocimiento lógico - matemático mediante la coordinación de las relaciones que ha ido estableciendo o creando anteriormente entre distintos objetos, por ejemplo, mediante la coordinación de la relación entre $<<$ tres $>>$ y $<<$ dos $>>$ llegará a deducir que $3+2=5$ y que $3 \times 2=6$.

Es pertinente mencionar también el conocimiento social, en él, sus fuentes últimas de construcción son las convenciones elaboradas por el ser humano. La característica principal es su naturaleza eminentemente arbitraria. Para adquirir el conocimiento social se necesita recibir la información de los demás. Este conocimiento requiere un marco de referencia lógico - matemático para su asimilación y organización. Muchos de los docentes que creen que los números por ejemplo deberían enseñarse por transmisión social no realizan la distinción fundamental entre el conocimiento lógico - matemático y el social. Las palabras «uno», «dos», "tres», son ejemplos de conocimiento social. Cada lengua posee un conjunto diferente de palabras para contar. Pero la idea de numero subyacente pertenece al 
conocimiento lógico - matemático, que es UNIVERSAL.

Ahora bien, en mis cortas experiencia con niños y jóvenes, al preguntarles por qué o como han llegado a tal o cual resultado, salen a flote algunos resultados que vienen a confirmar aun mas las anteriores ideas, es decir hay elementos dentro de sus razonamientos que no han sido enseñados por el docente, y que no se pueden enseñar, son el fruto de sus propias acciones mentales pero que, muchos maestros creen que eso ellos lo enseñaron, no alcanzando a entender que se trata del conocimiento lógico - matemático.

Veamos algunas de dichas experiencias:

1. Cierto día un aprendiz (Felipe, 7 años, grado tercerol de la división de números naturales se me acercó con el objeto de nivelarlo en ésta operación, pues según él sus compañeros ya habían asimilado el tema; en el fondo el problema tenía que ver con el manejo del algoritmo tradicional para dividir números naturales. como:

Empecé por preguntarle divisiones

$8 \div 2,7 \div 3,10 \div 4$, etc., ante las cuales él respondió: es 4 porque $2+2+2+2=8$, haciendo este conteo con los dedos de la mano, $=2$ por que $4+4=8$ y además "sobran dos". En fin para una serie de ejercicios "sencillos", siempre dió la respuesta contando con los dedos de la mano.

Antes de abordar otras divisiones «mas difíciles» quise asegurarme del manejo del residuo, ¿cuántas sobran y por qué?. Y por que la respuesta dada no era ni el número anterior ni el si- guiente al que obtenía. Esto fue respondido para mí en forma satisfactoria.

La experiencia continuó hasta abordar divisiones con números de varias cifras, pero ahora, ayudándose para el mismo conteo, con el papel y el lápiz (ver la revista notas de matemáticas \#33 de 1993 Universidad Nacional de Colombia).

Respecto a esta experiencia es preciso resaltar lo siguiente:

- Es de vital importancia para el enseñanza y el aprendizaje, conocer qué tanto sabe el alumno sobre cierta temática, pidiéndole además las explicaciones de dicho saber y partir de allí para organizar la instrucción.

- Muchos docentes ignoran o confunden dividir números naturales con el algoritmo para dicha operación, hasta el punto de escuchar afirmaciones como esta: Juanito no sabe dividir (conocimiento lógico - matemático), cuando sus deficiencias están en la reproducción memorística del algoritmo (conocimiento social).

2. Otro chico (Violeta, 7 años grado 3) buscó mi ayuda para efectos de la división, pero su preocupación inicial radicaba en que decía: "No me sé las tablas de multiplicar»; por esto, no podia avanzar gran cosa en la temática que la ocupaba.

Empecé mi trabajo aquí exactamente en su preocupación, preguntándole cosas como estas: $2 \times 3=$ ?, $3 \times 1=$ ?, 4 $\times 3=$ ?, $6 \times 2=$ ?, etc., respuestas que aparecían en forma inmediata y correcta, como aquellas que desean muchos profesores.

Luego pregunté por $2 \times 7,6 \times 6,8$ $x 4$, etc., las respuestas fueron acertadas, pero se demoró un poco, y ante 2 
$\times 9,8 \times 7,8 \times 9,9 \times 6$, sus respuestas aunque correctas se demoraron ahora mucho más.

Conclusión, las tablas de multiplicar se las sabía, pero le pregunté luego por qué se demoraba en unas respuestas mas que en otras. Ella así respondió:

$3 \times 4=12$ porque $3+3=6$ y $6+$ $6=12,8 \times 4=32$ porque $8+8=16$ y $16+16=32,8 \times 6=48$ porque $8+$ $8=16$ y $16+16=32,32+8=40 y$ finalmente $40+8=48$

$8 \times 7=56$, porque me sé la tabla del nueve, $9 \times 7=63$ y a este número le quito 7 , obteniendo finalmente 56 .

De igual forma, $8 \times 7=56$, porque me sé la tabla del $5,5 \times 8=40,40+8$ $=48$ y finalmente $48+8=56,9 \times 7$ $=63$, porque $10 \times 7=70$ y quitando a este último 7 , da 63 .

De esta experiencia concluyo lo siguiente:

- Existe premura en muchos docentes para que el alumno de la respuesta en forma rápida y correcta.

- Los procesos utilizados por la niña no fueron enseñados por el docente, son de su "propia autoría", estos no se pueden enseñar.

- En las diferentes formas de razonar del alumno, es donde se puede ob- servar la asimilación o no de determinado concepto, operación, definición o teorema.

- En saber respetar, escuchar y dar credibilidad a las respuestas y sus respectivos porqués, es donde cobra sentido nuestro quehacer.

No sobra decir que:

1. Para poder romper con los esquemas tradicionales de la escuela, se hacen necesarias varias cosas que van desde el diseño de políticas nacionales hacia una educación concebida como una verdadera inversión para una nación productiva, independiente, autónoma y con mentalidad competidora, hasta acabar con nuestras propias formas tradicionales de pensar y actuar. De esta manera podemos establecer un diálogo productivo entre profesores alumnos y entre profesores con otros miembros de la comunidad académica.

2. Los maestros deben ser agentes de comunicación entre alumnos, los saberes y los demás maestros.

3. Se deben proporcionar espacios para aprender y no proponerse a enseñar.

4. Por último retomo la afirmación de Nicolás Buenaventura: "El buen pedagogo es aquel que sabe resistir esa tentación demoníaca de enseñar y el mejor de todos es quien la resiste al máximo" (p. 87).

\section{Bibliografía}

ARDILA, J. (1993). Acerca de una experiencia pedagógica. Notas de matemáticas, No. 33, pp. 57 - 59. Universidad Nacional de Colombia.

BUENAVENTURA, N. (1997). El cuento del PEI. Santa Fe de Bogotá: Cooperativa Editorial Magisterio.

KAMII, C. (1994).El niño reinventa la aritmética. Madrid: Aprendizaje visor. 